\title{
Influence of carbores binder on the strength of Magnesia-Carbon
}

\section{materials}

\author{
Liu Jun ${ }^{*}{ }^{1}$, LiHongXia ${ }^{1}$, FengHaixia ${ }^{1}$ \\ ${ }^{1}$ State Key Laboratory of Advanced Refractories, Sinosteel Luoyang Institute of Refractories \\ Research Co., Ltd., Luoyang 471039, China \\ *liujun8690@163.com,
}

Keywords: carbores binder,magnesia-carbon,strength, environment-friendly.

Abstract. A new binder system was developed to produce Magnesia-Carbon matreials in a cold batch process. The binder system comprises a liquid carbores and a high-melting carbores powder. Both components are graphitizable thus leading to an anisotropic carbon system resistant to spalling and oxidation. The system combines the processing advantages of a resin-based binder and the high performance of a pitch based binder. The binder system complies with the stringent requirements of TRGS 551( the level of benzo[a]pyrene well below $50 \mathrm{mg} / \mathrm{kg}$ ). Lab tests indicated the viscosity of the liquid carbores allows a mixing process at room temperature, the medium and low temperature strength level of the new bonding system is comparable to pitch-bonded bricks and allow safe handling and lining.

\section{Introduction}

For the production of magnesia-carbon materials either coal tar pitch or phenolic resin is used as a binder. The superior performance of pitch-bonded bricks is related to the anisotropic, graphitizable coke structure of pitch after carbonization[1]. This mechanieal flexibility of the coke structure results in higher spalling resistance, better thermoshock stability and a higher strength at working temperatures. Pitch-bonded bricks are widely produced in Europe while they are not very common in Asia. The production of pitch-bonded bricks requires a hot mixing process and the standard coal tar pitch is considered hazardous for the environment due to the presence of toxic polyaromatic hydrocarbons like benzo[a]pyrene $(\mathrm{B}[\mathrm{a}] \mathrm{P})$. The content of $\mathrm{B}[\mathrm{a}] \mathrm{P}$ in coal tar pitch ranges from 10,000 to $15,000 \mathrm{mg} / \mathrm{kg}$. A recently developed new type of carbonaceous resin (CARBORES@ F) has a B[a]P content of below $300 \mathrm{mg} / \mathrm{kg}$ and allows the production of pitch-bonded bricks with less than $10 \mathrm{mg} / \mathrm{kg} \mathrm{B}$ [a]P thus meeting the EU regulation TRGS 551 [2, 3, 4]. However, CARBORES@ F still requires a hot mixing process.

In former work the soft bonding system have been studying by a combination of liquid phenolic resin and the carbores powder. the binder coke to some extent becomes anisotropic after carbonization resulting in an improved mechanieal flexibility and better oxidation resistance[5,6,7]. In most cases the replacement of phenolic resin powder by the carbores powder will reduce the cost for the total bonding system. An additional cost saving is usually achieved due to the fact that the soft bonding allows to reduce the amount of anti-oxidants. The amount of carbores powder may vary between 0.5 and $2 \%$. The complete or partial substitution of powder resin results in lower strength after curing. This is compensated or even over compensated during carbonization[8,910].

In this lab test, we adopt dual carbores bonding systems and Carbores/Resin bonding systems to 
produce Magnesia-Carbon samples, compared the physical index: bulk density, CCS (pressing), bulk density, porosity, CCS (hardening), bulk density, porosity, CCS and PLC (coking), study the strength change of different bonding systems at medium and low temperature.Lab tests indicated the viscosity of the liquid carbores allows a mixing process at room temperature, and the strength level of medium and low temperature for the new bonding systems is higher than that of resin-bonded samples and allow safe handling and lining.

\section{Experimental}

The bonding system are compared in accordance with the scheme described in Table 1.

Tab. 1. Batches

\begin{tabular}{|c|c|c|c|}
\hline batches & $\begin{array}{c}\text { 1and } \\
\mathbf{2}\end{array}$ & $\mathbf{3}$ and 4 & 5 and 6 \\
\hline Liquid resin & & $\bigcirc$ & \\
\hline Resin Powder & & & $\bigcirc$ \\
\hline Garbores Powder & $\bigcirc$ & $\bigcirc$ & $\bigcirc$ \\
\hline Liquid Garbores & $\bigcirc$ & $\bigcirc$ & $\bigcirc$ \\
\hline
\end{tabular}

\section{Raw materials}

For all tests magnesia-carbon model batch is used. The granulometric composition of the mixture was chosen for an optimal packing tightness with a max. Particle size of 5-0 mm. Each batch consists of highpurity fused magnesia, flake graphite and binders. The raw materials have properties according to Table2.3.4.

Tab.2. Properties of the dry raw materials used

\begin{tabular}{|c|c|c|c|c|c|c|}
\hline material & $\begin{array}{c}\mathbf{B . D} \\
\mathbf{g} / \mathbf{c m}^{\mathbf{3}}\end{array}$ & $\begin{array}{c}\mathbf{M g O} \\
\mathbf{\%}\end{array}$ & $\begin{array}{c}\mathrm{SiO}_{\mathbf{2}} \\
\mathbf{\%}\end{array}$ & $\begin{array}{c}\mathbf{C a O} \\
\mathbf{\%}\end{array}$ & $\begin{array}{c}\mathbf{F e}_{2} \mathbf{O}_{\mathbf{3}} \\
\mathbf{\%}\end{array}$ & $\begin{array}{c}\mathbf{B}_{2} \mathbf{O}_{\mathbf{3}} \\
\mathbf{\%}\end{array}$ \\
\hline Fused Magnesia & 3.5 & 97.6 & 0.85 & 0.88 & 0.62 & 0.01 \\
\hline
\end{tabular}

Tab. 3. Properties of resol and Novolak

\begin{tabular}{|l|c|c|}
\hline binder & resol & Novolak \\
\hline Viskosity at $\mathbf{2 0}^{\circ} \mathbf{C}$ [mPas] & $1500 \pm 150$ & \\
\hline Non-volatile matter at $\mathbf{1 3 5}^{\circ} \mathbf{C}$ [\%] & $80 \pm 5$ & \\
\hline Water content Karl-Fischer [\%] & $\leq 3$ & $\leq 5$ \\
\hline Free phenol [\%] & $\leq 5$ & $16 \pm 4$ \\
\hline Flow distance [mm] & & $10 \pm 1$ \\
\hline Hexa content [\%] & & $11 \pm 3$ \\
\hline Particle size $\mathbf{>} \mathbf{0 . 0 4 5}_{\mathbf{~ m m}[\%]}$ & & 365 \\
\hline Bulk density [g/dm & & \\
\hline
\end{tabular}

Tab. 4. Properties of carbores

\begin{tabular}{|l|c|c|}
\hline binder & CarboresP & CarboresT \\
\hline Description & Powder & Liquid \\
\hline Glass transition temperature $\left[{ }^{\circ} \mathbf{C}\right]$ & 213 & \\
\hline Coking value $(\mathbf{I S O} 6998)[\%]$ & 85.5 & 32 \\
\hline Benzo[a]pyrene content $[\mathbf{m g} / \mathbf{k g}]$ & 300 & 300 \\
\hline Granulometry $(<\mathbf{2 0 0} \mathbf{u} \mathbf{~ m})[\%]$ & 90 & \\
\hline Dynamic viscosity at $\mathbf{2 0}^{\circ} \mathbf{C}[\mathbf{m P a s}]$ & & 3200 \\
\hline
\end{tabular}




\section{Production of batches and sample preparation}

The bonding systems according to Table 1 are evaluated. The targeted carbon content of the carbonized brick is $12-13 \%$. All components are added and mixed in the sequence given in Table 5 . The total mixing time is 15 minutes. After a maturation of 2 hours in a closed vessel the batches are pressed to cylindrical $(\Phi 50 \times 50 \mathrm{~mm})$ and strip specimen $(25 \times 25 \times 125 \mathrm{~mm}) \quad$ in a hydraulic press at $200 \mathrm{MPa}$. Specimens are tempered in normal atmosphere up to $180^{\circ} \mathrm{C}$ according to a temperature profile typically used for resin-bonded bricks. After tempering all specimens were carbonized in inert atmosphere by heating up to $400^{\circ} \mathrm{C}, 600^{\circ} \mathrm{C}, 800^{\circ} \mathrm{C}$ and $1000^{\circ} \mathrm{C}$ respectively and a final holding time of 5 hours.

By using three-point bending machine, Hot modulus of rupture (HMOR) can be tested, testing furnace was heated up to $400^{\circ} \mathrm{C}, 600^{\circ} \mathrm{C}, 800^{\circ} \mathrm{C}, 1000^{\circ} \mathrm{C}$ and $1400^{\circ} \mathrm{C}$ in inert atomphere and the final holding time is $30 \mathrm{~min}$, the speed of increase the load at $10 \mathrm{~N}$.min-1, until the point of rupture.

Tab. 5. Composition of batches and mixing sequence

\begin{tabular}{|c|c|c|c|c|}
\hline sequence & batch & component & Amount[\%] & Total[\%] \\
\hline 1 & all & Fused magnesia 3-5mm & 25 & 25 \\
\hline 2 & all & $\begin{array}{c}\text { Fused magnesia } \\
\text { 3-1 mm } \\
\end{array}$ & 20 & 45 \\
\hline 5 & all & $\begin{array}{c}\text { Fused magnesia } \\
1-0 \mathrm{~mm} \\
\end{array}$ & 20 & 65 \\
\hline 7 & all & Fused magnesia $0.088 \mathrm{~mm}$ & 25 & 90 \\
\hline 4 & all & Flake graphit & 10 & 100 \\
\hline $\begin{array}{l}3 \\
6\end{array}$ & 1 & $\begin{array}{l}\text { CarboresT } \\
\text { CarboresP }\end{array}$ & $\begin{array}{l}+2.0 \\
+1.3\end{array}$ & 103.3 \\
\hline $\begin{array}{l}3 \\
6\end{array}$ & 2 & $\begin{array}{l}\text { CarboresT } \\
\text { CarboresP }\end{array}$ & $\begin{array}{l}+2.5 \\
+1.5 \\
\end{array}$ & 104 \\
\hline $\begin{array}{l}3 \\
6\end{array}$ & 3 & $\begin{array}{l}\text { Resol + Carbores T } \\
\text { CarboresP }\end{array}$ & $\begin{array}{c}+1.5+1.5 \\
+1.3\end{array}$ & 104.3 \\
\hline $\begin{array}{l}3 \\
6\end{array}$ & 4 & $\begin{array}{c}\text { Resol + CarboresT } \\
\text { CarboresP }\end{array}$ & $\begin{array}{c}+1.5+1.5 \\
+1.5 \\
\end{array}$ & 104.5 \\
\hline $\begin{array}{l}3 \\
6\end{array}$ & 5 & $\begin{array}{c}\text { CarboresT } \\
\text { CarboresP + Novolak } \\
\end{array}$ & $\begin{array}{c}+2.0 \\
+0.7+0.7 \\
\end{array}$ & 103.4 \\
\hline $\begin{array}{l}3 \\
6\end{array}$ & 6 & $\begin{array}{c}\text { CarboresT } \\
\text { CarboresP + Novolak }\end{array}$ & $\begin{array}{c}+2.5 \\
+0.8+0.8\end{array}$ & 104.1 \\
\hline
\end{tabular}

\section{Results and discussion}

\section{Density, cold crushing strength and porosity}

Results on bulk density, porosity, permanent linear change and cold crushing strength measured at room temperature are shown in Table 6. The Resin/Carbores sample show the highest densities. The Carbores/Resin powder sample are slightly lower while the the dual carbores sample show the lowest . Apparently, this does not translate into inferior product properties.

After tempering the resin/carbores sample have the highest strength while for carbores the strength is lower. This can be explained by the fact that both the liquid carbores as well as the 
carbores powder do not cure at tempering temperature. After carbonization, the strength level is comparable to pitch-bonded bricks.

Tab. 6. Results on specimens after moulding, hardening and coking

\begin{tabular}{|c|c|c|c|c|c|c|c|}
\hline batch & & 1 & 2 & 3 & 4 & 5 & 6 \\
\hline \multirow{2}{*}{$\begin{array}{c}\text { After } \\
\text { pressing }\end{array}$} & $\mathrm{CCS}[\mathrm{KN}]$ & 21 & 20 & 27 & 29 & 18 & 16 \\
\hline & B.D $\left[\mathrm{g} / \mathrm{cm}^{3}\right]$ & 2.92 & 2.99 & 2.99 & 2.98 & 2.94 & 2.94 \\
\hline \multirow{3}{*}{$\begin{array}{l}\text { After } \\
\text { hardening/ } \\
\text { tempering }\end{array}$} & CCS[MPa] & 61 & 68 & 72 & 75 & 72 & 66 \\
\hline & B.D $\left[\mathrm{g} / \mathrm{cm}^{3}\right]$ & 2.95 & 2.94 & 2.94 & 2.95 & 2.91 & 2.91 \\
\hline & OP[\%] & 7.6 & 6.9 & 5.9 & 5.2 & 8.1 & 7.5 \\
\hline \multirow{6}{*}{$\begin{array}{c}\text { After } \\
\text { coking }\end{array}$} & CCS[MPa] & 41 & 41 & 54 & 43 & 37 & 40 \\
\hline & B.D $\left[\mathrm{g} / \mathrm{cm}^{3}\right]$ & 2.86 & 2.87 & 2.85 & 2.85 & 2.89 & 2.83 \\
\hline & OP[\%] & 13.3 & 12.0 & 12.4 & 13.0 & 12.1 & 12.7 \\
\hline & PLC in PD & 0.15 & 0.21 & 0.18 & 0.33 & 0.1 & 0.17 \\
\hline & [\%] & & & & & & \\
\hline & $\begin{array}{c}\mathbf{P L C} \perp \mathbf{P D} \\
{[\%]}\end{array}$ & 0.09 & 0.05 & 0.15 & 0.16 & 0.01 & 0.01 \\
\hline \multicolumn{8}{|c|}{$\begin{array}{c}\text { CCS = Cold Crushing Strength, } \mathrm{BD}=\text { Bulk Density, } \mathrm{OP}=\text { Open Porosity, } \mathrm{PLC}=\text { Permanen } \\
\text { Linear Change, in } \mathrm{PD}=\text { in press direction, } \\
\perp \mathrm{PD}=\text { perpendicular to press direction }\end{array}$} \\
\hline
\end{tabular}

It indicates that all samples keep good moulding function.Compared to pure resin binder sample with 3.5\% liquid resin, Quantity of 1.5-2.0\% Carbores liquid binder can meet the moulding requirement well.

\section{Strength variation at different temperature}

Fig1 shows the development of the CCS versus temperature of specimen .As fig 1 shows, No 2\# shows difference strength variation(temperature range of $400-600^{\circ} \mathrm{C}$ ) Compared to the other binder methods, It gets the highest strength value among all the bonding methods, which is the low point to traditional resin bonding. The strength value of No1\#,3\#,4\#,5\# rise apparently (temperature range from 400 to $600^{\circ} \mathrm{C}$ ). In all test samples, batch $2 \#$ and $3 \#$ have good synthesized physical index (No $0 \#$ is pure resin binder samples).

fig 1 Strength Comparison at different tempering temperature

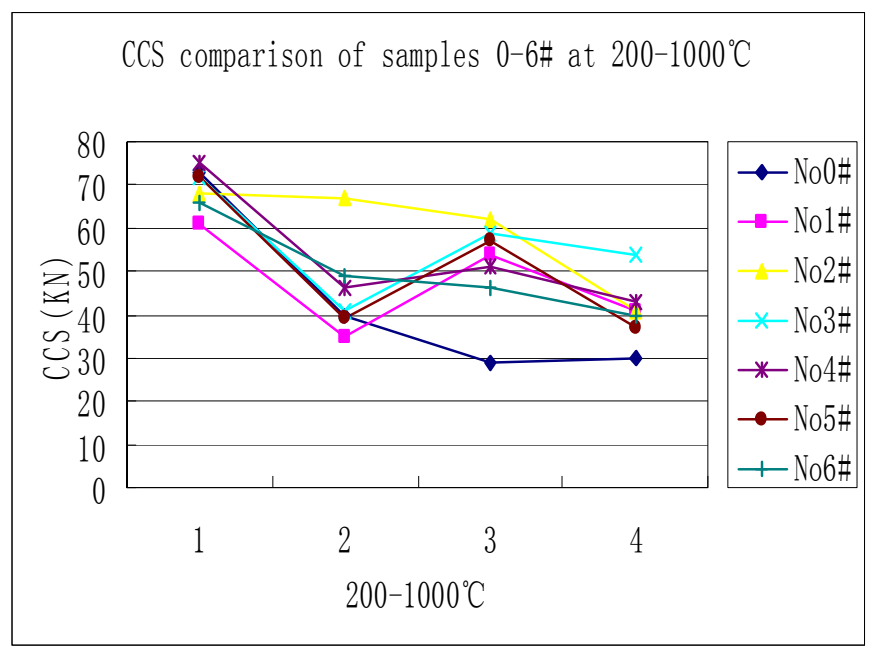




\section{HMOR variation comparison}

Fig 2 shows modulus of rupture (HMOR) comparison of different bonding samples at $200^{\circ} \mathrm{C}, 400^{\circ} \mathrm{C}, 600^{\circ} \mathrm{C}, 1000^{\circ} \mathrm{C}$. As result shows, the HMOR value of all test samples apparently higher than that of resin bonding No0\#. The increase of strength at temperature range above $400^{\circ} \mathrm{C}$ results from the development of a semi-coke structure and later by the final coke structure.

fig $2 \mathrm{HMOR}$ comparison at $200-1000^{\circ} \mathrm{C}$

fig 3 HMOR comparison at $1400^{\circ} \mathrm{C}$
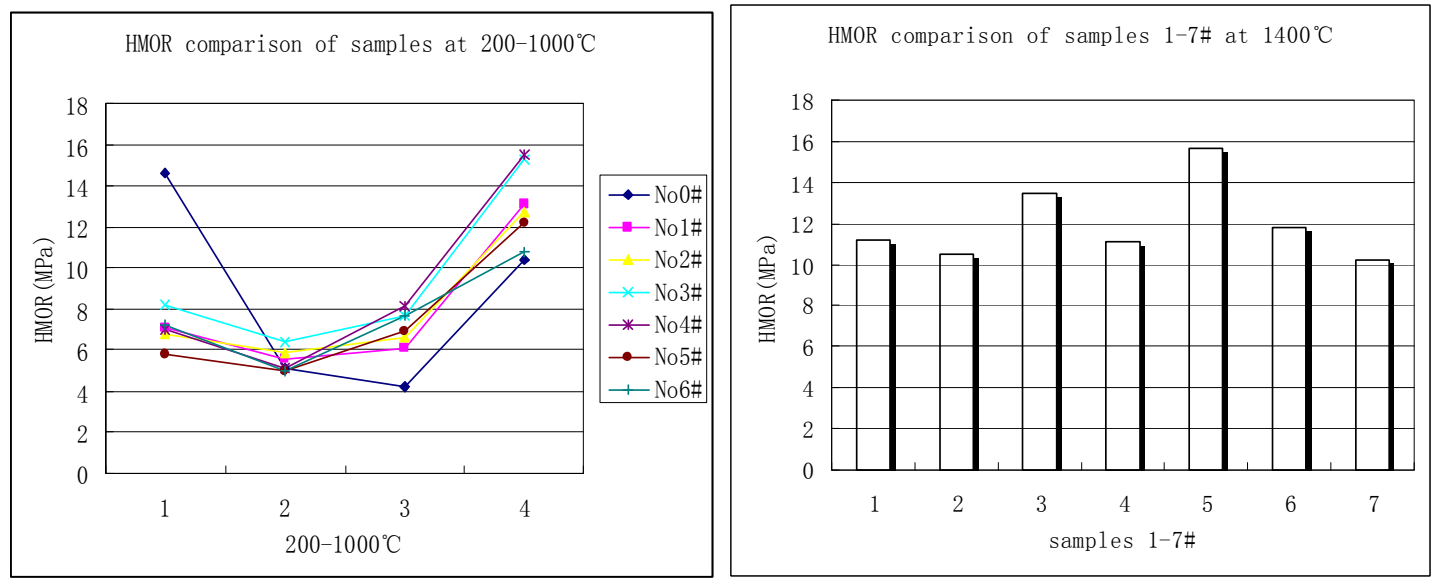

Fig 3 shows hot modulus of rupture (HMOR) comparison at $1400^{\circ} \mathrm{C}$, As result shows, the HMOR value of all samples is comparable with sample 7\#, expecially notice that the HMOR value of sample $7 \#$ ( with antioxidants) is relatively lower.

The strength-temperature curve can be explained by the fact that the solubility of carbores powder in the liquid carbores raise with increasing temperature and leads to a better wetting of the matrix and therefore to an increase of the strength. On the other hand with rising temperature more and more volatile components evaporate and create new porosity. These contrary reactions lead to a lower strength in the range of $200-400^{\circ} \mathrm{C}$. The increase of strength at temperatures range above $400^{\circ} \mathrm{C}$ results from the development of a semi-coke structure and later by the final coke structure.

\section{Conclusions}

In laboratory scale it was shown that the bonding system consisting of a liquid Carbores and a Carbores powder provides results comparable to the existing bonding systems. the viscosity of the liquid carbores allows a mixing process at room temperature, the medium and low temperature strength level for the new bonding system is comparable to pitch-bonded samples and allow safe handling and lining. the new carbores binder belong to environment-friendly materials. The number of tested recipes still leaves room for further optimization, Large scale industrial trials have started to confirm the laboratory results.

\section{References}

1.Aneziris, e. G., et al.: Magnsia Carbon Bricks - A high-Duty Refractory Material. Interceram Refractories Manual 2003, p. 22-27.

2.Buchebner, G., et al.: Carbon-Bonding - a New Milestone on Low Emission Magnesia-Carbon Bricks., 7th Biennial Worldwide Congress UNITECR'O1 Vol. 1 (2001) p.324-335.

3.Borzov, D., et al. : Technological and environmental comparis on of different carbon-binders for 
$\mathrm{MgO}-\mathrm{C}$ refractories. 44th International Colloquium on Refractories. Aachen (26-27 September 2001), p. 50-52.

4.Buchebner, G., et al.: ANKERSYN - A New Generation of Carbon-Bonded Magnesia Carbon Bricks. RHI Bulletin, The Journal of Refractory Innovations, 1/2004, p. 24-27.

5.Boenigk, W.: Pech stämmige Bindemittel für Feuerfestprodukte. 25. Feuerfestseminar (VDEH-Seminar 71/94), 18.-21.12.94 in Bad Neuenahr.

6.Effect of Carbores on Properties of MgO-C Bricks (Phase 2)., Luoyang Institute of Refractories Research (2004), p. 2-17.

7. ti,Batiel et.al,, Ptiings of InternationalSymposiumon Refractories, China, 502 (1988).

8. G,Matvin, Ceram.Eng. Sa. Proc, 14 (1-2) 468-471 (1993).

9.A.K.Bose,et.al,, Proceedings of Seminar on lnd nws experience ladle metallu $\sim$, Du $\sim$ apur, B3-I (1990).

10. T.tirimoto, et.al., P-ings of the fi $\sim$ International conference on R ,Tokyo, 115,(19S3). 